\title{
An IoT based Cigarette Smoke Detection System for Green Environment
}

\author{
Mohammad Alif Haika Muhamad ${ }^{1}$, Murizah Kassim $^{1,2}$, Siti HazurahIndera Putera ${ }^{1}$ \\ ${ }^{1}$ Faculty of Electrical Engineering, UniversitiTeknologi MARA, 40450 Shah Alam, Selangor, MALAYSIA. \\ ${ }^{2}$ Enabling Internet of Things Technologies Research Group (ElIoTT), Faculty of Electrical Engineering, UniversitiTeknologi \\ MARA, 40450 Shah Alam, Selangor, MALAYSIA. \\ murizah@uitm.edu.my
}

\begin{abstract}
This paper presents prototype development of an adaptive cigarette smoke detection systemand analysis that adaptively senses the condition of gas. The sense data is logged and sent to a webpage adaptively and monitored online. Air pollutions are an issue for safe and healthy environment today. There are few problems that have been encounter from safety environment such as air pollutions are growing rapidly worldwide, second problem is to detect the non-smell gas which present high level of pollutions in the air. This project identified three goals where improved of current system. Then, parameters are compared and used to develop the new system. Secondly, a prototype gas monitoring system is developed based on hardware and system that sense data that are logged to a webpage using Arduino UNO controller. The third objective is to test the system at one area that able to measure the existence and level of gas focus on air pollution. The system is automatic adaptively sense gases and updated its condition to a webpage. The developed system used Arduino UNO controller. The system has identified gas concentration by using gas sensors MQ135 and using ESP8266 Wi-Fi module for communications medium. Results present gas of cigarette smoke that sensed between 250 and 500ppm at 0.5 -meter distance. Analysis presents at range from $0 \mathrm{ppm}$ to $100 \mathrm{ppm}$ at distance at 1 meter. This paper is significant that developed an adaptive monitor of cigarette smoking as detector system that alerts society on the air condition at an environment. The result is as guided to Environmental Department to monitor air liquid unhealthy condition and actions are taken to monitor the condition of green environment.
\end{abstract}

Key words: IoT, Detection, Arduino

\section{INTRODUCTION}

Recent study reports many health issues due to cigarette smoking that impact the smokers and also people who stay at surround the smokers $[1,2]$. Growing concern over the toxicity of environmental pollutants and atmospheric aerosols has prompted research to investigate the mechanisms involved in lung injury and repair following exposure to toxicants [3]. A comparative assessment of the biological impact of a heated tobacco aerosol from the tobacco heating system (THS) 2.2 and smoke from a combustible $3 \mathrm{R} 4 \mathrm{~F}$ cigarette that has been done. Human body cultures were exposed to an aerosol from THS2.2 that is a candidate modified-risk tobacco product or $3 \mathrm{R} 4 \mathrm{~F}$ smoke at similar nicotine concentrations. There are lot of losses caused by cigarette smoke and cigarette smoke itself can disturb the people around like the health of others. Some restrictions in certain rooms for smoking by giving a sign that smoking is prohibited are done but some people sometimes ignore the signed. One recent study did presented a system that was embedded to give warnings to people who smoke in rooms that cannot smoke[4]. A system toxicology approach was enabling with a comprehensive exposure impact assessment on the environment. A Study on passive detection of cigarette smoking offers potential for considerable benefits to researchers exploring smoking behaviour and designing precision behaviour change interventionsthat has been done. A number of systems have been developed that either use bespoke sensing technology, or rely on connected smartphones to run analytical software or presented data through webpages and accesses online [5, 6]. One study has presented a developed Stopwatch, a system for passive detection of cigarette smoking that runs on a smart watch and does not require additional sensing or a connected smartphone. The methods used in the system presented motion data from the accelerometer and gyroscope in an Android smart watch to detect the signature hand movements of cigarette smoking. It uses a three-stage analytical pipeline to transform raw motion data into motion features, and in turn into individual drags and instances of smoking. This pipeline runs on the smart watch, and does not require a smartphone [7]. They validated the system in daily smokers which presented $\mathrm{n}=13$ in laboratory and free-living conditions running on an Android LG G-Watch. In free-living conditions, over a 24hour period, the system achieved precision of $86 \%$ and recall of $71 \%$. Similar to this research that aim to develop an adaptive gas cigarette smoke prototype detection system that adaptively sense the condition of gas of cigarette smoke and logging data is sent to a webpage that presented on ThingSpeak webpages. ThingSpeak is an Internet of Things (IoT) API and application to store and recoup data from things using the HTTP tradition over the Internet or through a Local Area Network or web based system[8]. This system can monitor the smoke that affects surrounding air pollution.

This project aims to presents a new cigarette smoke detector system that used Arduino as the controller and control board that is easy to program and can connect to a wide variety of hardware. The microcontroller produced by the Arduino and considering the Atmel's ATmega328 microcontroller. To transfer the data from Arduino to 
webpages is using ESP8266 Wi-Fi Module. The ESP8266 can do either facilitating an application or offloading all Wi-Fi organizing capacities from another application processor. There are few problems that to be encounter from safety environment. The major problem is to detect the cigarette smoke that can be smelled ornot depended on the distance people staying from the smokers. According to Greenhouse Gases (GHG) emissions are growing rapidly worldwide and level of gases in air pollution that also contributed from cigarette smoke. This developed system used MQ135 as sensor to detect gas of CS to support green environment. After the sensor sense, the gas from surrounding the gas reading is uploading to a Webpages. Webpages display CS data logging result in graphs. The prototype CS monitoring system is developed based on hardware and system that sense data and able to measure the existence and level of CS in air. Recent monitoring research presented indoor air quality is critical in America that spends $93 \%$ of their life indoors, and around 6.3 million children suffer from asthma. It is identified passively and unobtrusively monitors the asthma patient's environment to detect the presence of asthma-exacerbating activities that are smoking using the Foobot sensor. A proposes data-driven approach to develop a continuous monitoring-activity detection system aimed at understanding and improving indoor air quality in asthma management. The study presented successfully able to detect a high concentration of particulate matter, volatile organic compounds, and carbon dioxide during smoking activities. It detected smoking with an error rate of 1 and obtained an overall 95.7 per cent accuracy classification across all events control and smoking. The results presented system that allow doctors and clinicians to correlate potential asthma symptoms and exacerbation reports from patients with environmental factors without having to personally be presentedand determine the air condition[9, 10].

New technology that expressed data with Information Technology is Internet of Things (IoT) system that able to presents the affected area of CS gas or to monitor health[11]. Study presented air is exposed to fine particulate matter in the home from sources such as smoking put children, at risk of detrimental health effects. A design mobile applications which named as "jomQuit" was able to generate graph pattern on smoking cessation[12]. Some locations are affected by air pollutions cause of mechanical creation which presented location of gas focus [13]. Air pollutions which also come from CS are serious issues that related to health issues such as lungs and asthma disease [14]. The present biological checking implemented to detect gases are massive. Recent research have started to build gas sensors and sensor structures to detect air pollution or gases [15]. Some sensors exist are the temperature modification for GHG content growing that are vapour, methane, carbon dioxide and ozone. The effect of different GHG varies with their distinctive concentration and warming potential that extent of $\mathrm{CO} 2$ for GHG makes it the standard GHG and produces the principal consequences of a hazardous climatic deviation [16]. Different gasses also display patterns of data categories such as a research on motorcycle combustion gasoline engine carburettor system through the detection of exhaust emissions that has been done including carbon monoxide that can be very dangerous [17]. Preparations for the prototype development in adaptively detected the CS gases, few comparisons on sensors parameters and types have been studied and compared from the previous research. Table 1 presents the comparison result on Gas Monitoring systems based on type of sensors, detected gases, output display, and used controller for the systems.

Table 1.Comparison of the monitoring gas system

\begin{tabular}{|c|c|c|c|}
\hline $\begin{array}{l}\text { Type of the } \\
\text { sensor }\end{array}$ & $\begin{array}{l}\text { Detected } \\
\text { gases }\end{array}$ & Output & Controller \\
\hline $\begin{array}{c}\mathrm{CO}, \mathrm{CO} 2, \mathrm{CH} 4 \\
\text { sensors [18]. }\end{array}$ & $\begin{array}{c}\text { Carbon } \\
\text { monoxide, } \\
\text { carbon } \\
\text { dioxide, and } \\
\text { methane }\end{array}$ & $\begin{array}{l}\text { Compu } \\
\text { ter and } \\
\text { mobile } \\
\text { phone }\end{array}$ & ARDUINO \\
\hline $\begin{array}{c}\text { Carbon } \\
\text { dioxide } \\
\text { (CDM4161, } \\
\text { combustible } \\
\text { gas } \\
\text { (FCM6812), } \\
\text { carbon } \\
\text { monoxide } \\
\text { (TGS 5042), } \\
\text { and air quality } \\
\text { (AM 1- } \\
\text { 2602).[19] }\end{array}$ & $\begin{array}{c}\text { carbon } \\
\text { dioxide, } \\
\text { carbon } \\
\text { monoxide and } \\
\text { air quality }\end{array}$ & $\begin{array}{l}\text { Compu } \\
\text { ter and } \\
\text { cellula } \\
\mathrm{r} \\
\text { phone }\end{array}$ & ARDUINO \\
\hline $\begin{array}{l}\text { MQ-2 and } \\
\text { MQ-7 sensors } \\
\text { [20]. }\end{array}$ & $\begin{array}{l}\text { Isobutene, } \\
\text { Butane, LPG }\end{array}$ & $\begin{array}{c}\text { LCD } \\
\text { DISPL } \\
\text { AY, } \\
\text { alarm } \\
\text { and } \\
\text { sent } \\
\text { SMS } \\
\text { to } \\
\text { hand } \\
\text { phone. }\end{array}$ & PIC $16 F 877$ \\
\hline $\begin{array}{c}\text { MQ-6 sensor } \\
{[21] .}\end{array}$ & $\begin{array}{c}\text { propane and } \\
\text { butane }\end{array}$ & $\begin{array}{c}\text { Sendin } \\
\text { g SMS } \\
\text { to a } \\
\text { particu } \\
\text { lar } \\
\text { Mobile } \\
\text { numbe } \\
\text { r and } \\
\text { LCD } \\
\text { display }\end{array}$ & $\begin{array}{c}\text { PIC } \\
16 \mathrm{~F} 877 \mathrm{~A}\end{array}$ \\
\hline $\begin{array}{c}\text { Air } \\
\text { sensors[22] }\end{array}$ & $\begin{array}{c}\text { Carbon } \\
\text { monoxide gas } \\
\text { CO is } \\
\text { odourless, } \\
\text { colourless, } \\
\text { tasteless and } \\
\text { highly } \\
\text { poisonous gas }\end{array}$ & $\begin{array}{c}\text { LCD } \\
\text { DISPL } \\
\text { AY }\end{array}$ & $\begin{array}{c}\text { Arduino } \\
\text { atmega328 } \\
\text { microcontroll } \\
\text { er board }\end{array}$ \\
\hline $\begin{array}{c}\text { metal oxide } \\
\text { (MOS) and } \\
\text { electrochemic } \\
\text { al (EC) } \\
\text { sensors [23]. }\end{array}$ & $\begin{array}{c}\text { carbon } \\
\text { monoxide } \\
(\mathrm{CO}), \text { ozone } \\
(\mathrm{O} 3), \text { nitrogen } \\
\text { dioxide } \\
(\mathrm{NO} 2), \\
\text { ammonia, } \\
\text { hydrogen }\end{array}$ & $\begin{array}{l}\text { Smartp } \\
\text { hone }\end{array}$ & - \\
\hline
\end{tabular}




\section{sulphide, and \\ total volatile \\ organic \\ compounds}

(TVOCs)

\section{MATERIAL AND METHOD}

The methodology consists of hardware, software, and programming languages for the prototype development process.

\subsection{Block Diagram}

Figure 1 shows the functional of block diagram of the adaptive CS gas monitoring prototype system that adaptively sense the condition of CS gas and data logging is sent to online webpages. The sensor has been set up to detect the CS gas on real time. The MQ135 sensor has detected the CS gas in the air space. Then the logged data is sent to the controller of the system. Arduino UNO is the brain that controls the whole project process. Arduino UNO analysed the data or information and transmits the data by the ESP8266 Wi-Fi communication module. As the output, the webpages displayed all values of CS gas in graphs on captured time.

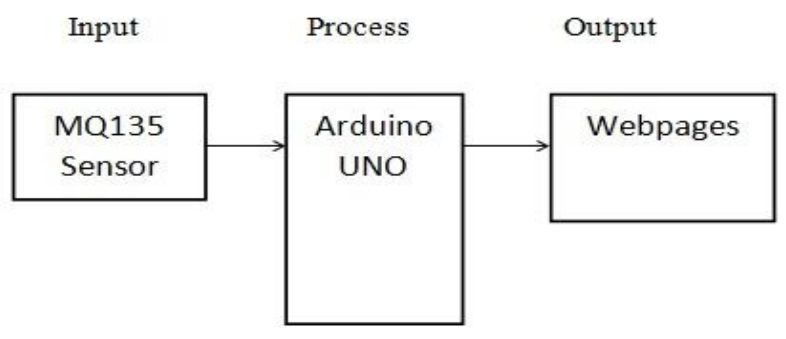

Figure. 1. System's Block Diagram

\subsection{Flowchart of the System Development}

Figure 2 shows the flowchart of the system that accessed the hardware, software, and system development. The primary equipment that is used for this project is Arduino UNO, MQ135 sensor, ESP8266 Wi-Fi Module. The software is used which is Arduino IDE and ThingSpeak as a webpage. Next, the forms of identifying the parameter of the project would direct that are should recognize the gas sensor. Then, the Arduino UNO similarly as the primary controller that regulated the entirety system will be produced. Then, ESP8266 transfer the data to webpages. Webpages will display the value of the gas in a graph.

\subsection{Hardware Design}

Figure 3 shows the hardware design of a gas sensor to detect gas. MQ135 is used in this project because MQ135 is an Air Quality Sensor suitable for detecting benzene, alcohol and smoke as used in one research [24].Table 2 presents the Arduino Uno microcontroller parameters that produced by the Arduino and considering the Atmel's ATmega328 microcontroller. Arduino Uno is a microcontroller board. "Uno" implies one in Italian and the Uno board is the most recent in a progression of USB (Universal Serial Bus). In the meantime, Arduino load up is a reference demonstrate for the Arduino stage. The Arduino Uno board has a USB association, a $16 \mathrm{MHz}$ artistic resonator, an ICSP header, a power jack, a reset catch, 6 simple sources of info furthermore 14 computerized input/yield pins which 6 can be utilized as PWM yields.

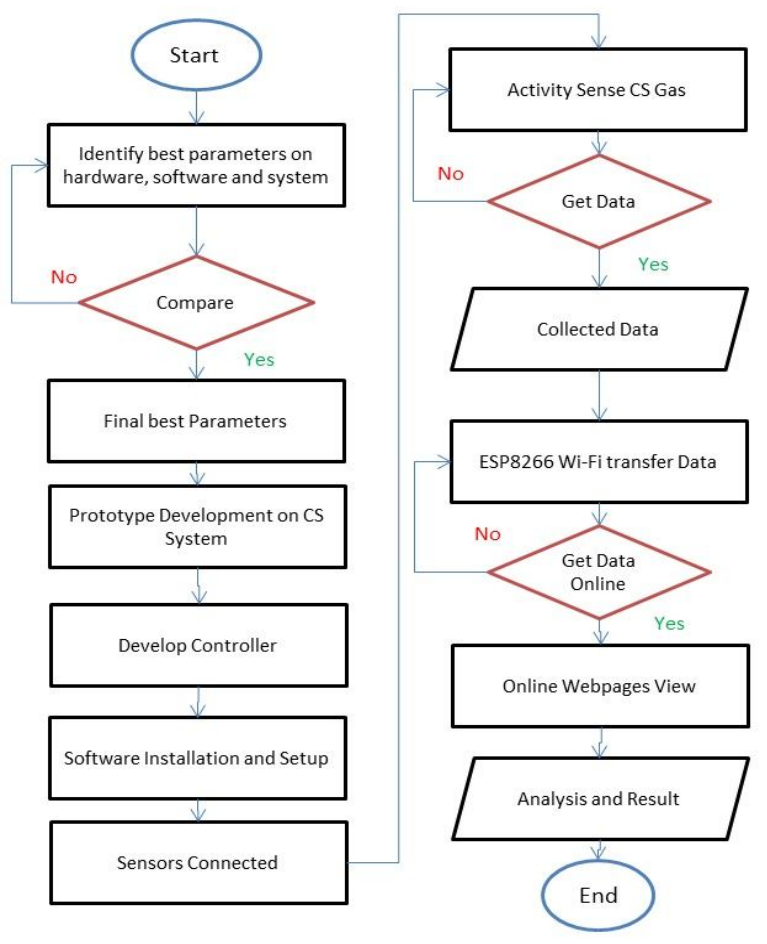

Figure 2.System's flowchart
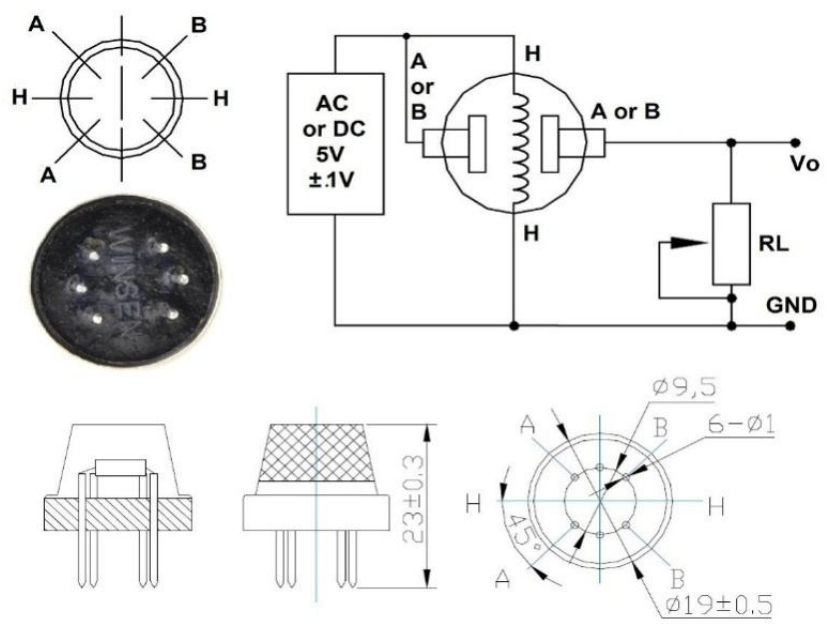

Figure3. Hardware design of MQ135 sensor

Table 2. Description of Arduino uno

\begin{tabular}{cc}
\hline Specification & Description \\
\hline Microcontroller & ATmega328 \\
Operating Voltage & $5 \mathrm{~V}$ \\
Input Voltage & $7-12 \mathrm{~V}$ \\
(recommended) & \\
Input Voltage (limits) & $6-20 \mathrm{~V}$ \\
Digital I/O Pins & 14(of which 6 provide PWM \\
output) \\
Analog Input Pins & 6 \\
DC Current per I/O & $40 \mathrm{~mA}$ \\
Pin & $50 \quad \mathrm{~A}$ \\
DC Current for 3.3V & \\
Pin &
\end{tabular}




\subsection{Circuit Design}

Figure 4 shows the circuit design for MQ135 sensor. The 5 Volts from Arduino UNO is utilized for this sensor. Load Resister is equal to $10 \mathrm{~K}$ which this sensor also has been used to measure air quality from COTS gas sensors [25] .

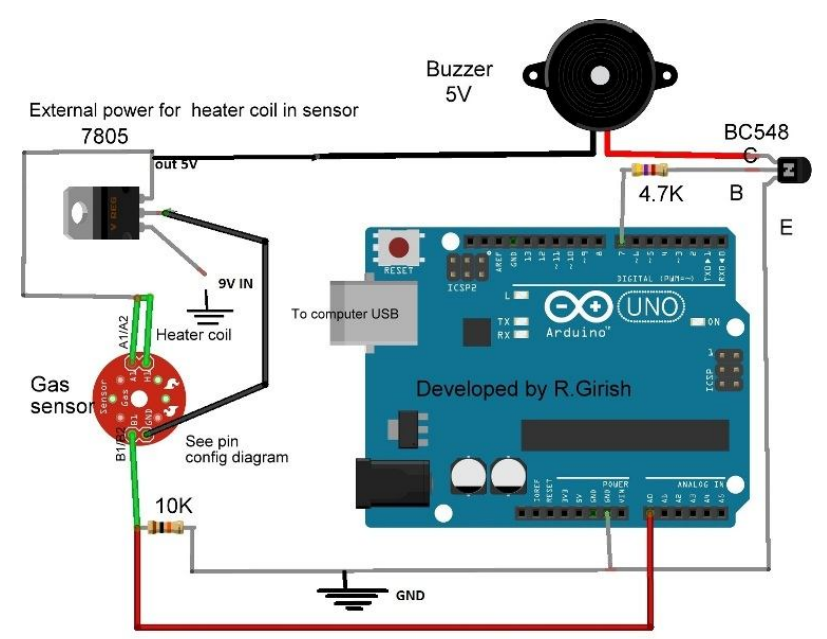

Figure 4Circuit of the MQ135 sensor

The sensor takes a couple of minutes or so to warm up to reach optimal operating condition. Until it reaches optimal working temperature, the values in the serial monitor fluctuates high and low. It stabilizes after few minutes. In the program, the user can set the threshold value, it must be done only after careful observation on normal ambient concentration value in the serial monitor. For instants, if the value fluctuates from 400 to 430 , the threshold must set well above, like 500. It must not trigger the buzzer falsely.

\subsection{CS Data Collection time}

Table 3 shows schedule of data collection that has been tested using the developed prototype system for data analysis running on real environment area.

Table 3. Schedule of data CS data collection

\begin{tabular}{ccccc}
\hline Schedule & Time & $\begin{array}{l}\text { Distance } \\
\text { from } \\
\text { Sensors } \\
\text { (Meter) }\end{array}$ & $\begin{array}{l}\text { Interval } \\
\text { Time } \\
\text { (Second) }\end{array}$ & Area \\
\hline Time 1 & $\begin{array}{c}12.50 \text { PM } \\
\text { to } 1.00 \\
\text { PM }\end{array}$ & 0.5 & 15 & $\begin{array}{c}\text { Open } \\
\text { Area }\end{array}$ \\
\hline Time 2 & $\begin{array}{c}12.45 \text { PM } \\
\text { to } 1.15 \\
\text { PM }\end{array}$ & 1 & 15 & $\begin{array}{c}\text { Open } \\
\text { Area }\end{array}$ \\
& $\begin{array}{c}\text { 2.15 PM } \\
\text { to } 2.30\end{array}$ & 1 & 15 & $\begin{array}{c}\text { Air } \\
\text { Condition } \\
\text { Poom }\end{array}$ \\
\hline & PM 3 & & & \\
\hline
\end{tabular}

\section{RESULTS AND DISCUSSION}

Result shows the developed of prototype of CS detection system successfully done and tested. Figure 5 shows the configuration of MQ135 sensor that is effective actualized in the prototype system. The sensor detects the CS gas present in the area. Then, Arduino UNO receives the input. ESP8266 Wi-Fi module sends the data to webpages. User can monitor gas on the webpages that display the value of
CS gas in ppm a graph. Identified areas presented captured data of CS gases at the surrounding areas when tested. The ESP8266 Wi-Fi module is set to send the data every 15 seconds to webpage. If the gas sensor MQ135 detects smoke, the reading of the smoke gas is appeared in serial monitor Arduino Uno. This reading is plotted in graphs using ThingSpeak webpage. Results show three different graphs from three different time situations in a selected area.

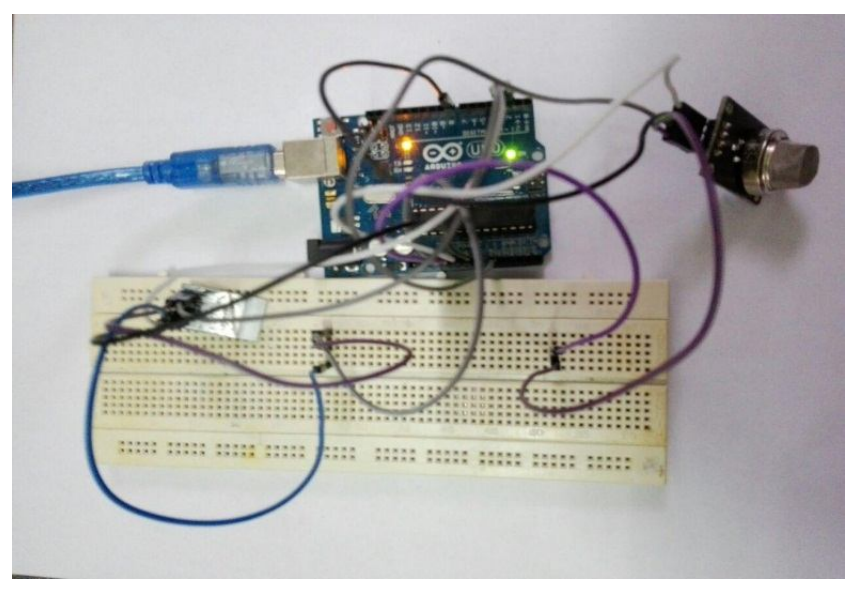

Figure 5. Circuit Design of MQ135 and ESP8266 WiFi module

Figure 6 presents collected CS gases at schedule of time 1 which is from 12.51PM to $12.55 \mathrm{PM}$. Tested is done at an environment where seen nobody smoking in the areas. Thus, sensor MQ135 responded and no detected data is collected. Later at time $12.52 \mathrm{PM}$, the graph presents a starting rise from $0 \mathrm{ppm}$ to reaching 500ppm due to cigarette smoke gas detected at distance of 0.5 meter from the gas sensor. MQ135 sensor become less sensitive in distance to the cigarette smoke if the distance is moving farer which shows its responded graph at the time 12.55PM a low cigarette smoke gas is given the response graph shows reading below 250ppm. Analysis present from time 12.54 to 12.55 the value of the gas is between 250 and $500 \mathrm{ppm}$.

\section{Field 1 Chart $\quad 0<x$}

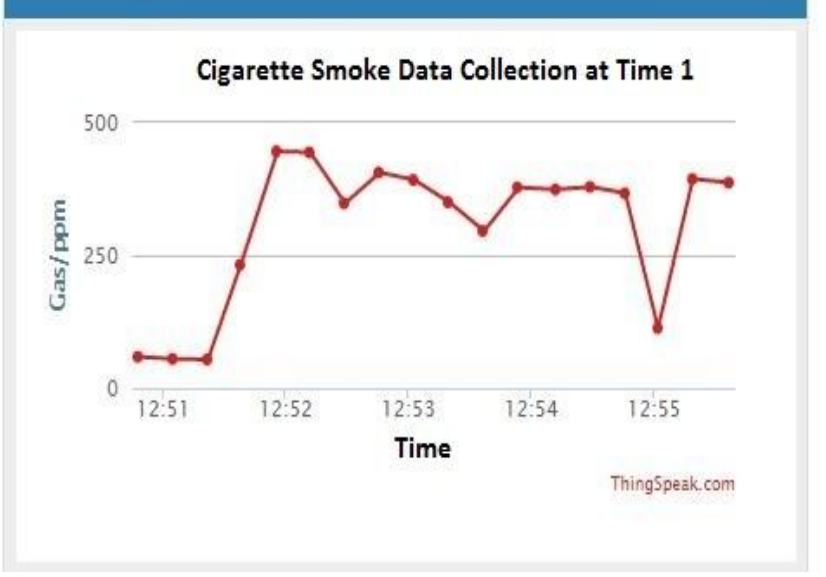

Figure 6. Published of CS Data online at Time 1

Figure7 shows the CS gases collected at time 2 which is at 1.30PM to 2.15 PM. The interval data collected time is 
every 10 seconds at 0.5 meter and the values is reaching 300ppm. Later a distance is move to 1 meter that shows CS gasses reading moving down that present an average of below 100ppm readings started from 1.30 PM to 2.15 PM.Figure 8 shows the CS gas data collected at schedule of Time 3 in an air condition room area. The CS gas reading is taken from $14.15 \mathrm{PM}$ to $14.30 \mathrm{PM}$ at distance 1 meter. The reading shows a decreasing data of CS from $70 \mathrm{ppm}$ to $60 \mathrm{ppm}$ within 15 minutes in time. Overall, the prototype of the CS detector system presented successfully, simple, affordable, and effective CS gas monitoring system. It will help to monitor gas for safety environment. This project benefits to monitor and alert society on the air condition at an environment. The result can be taken as guided to Environmental Department to monitor CS gasses level in an area for health protections as alerts to society.

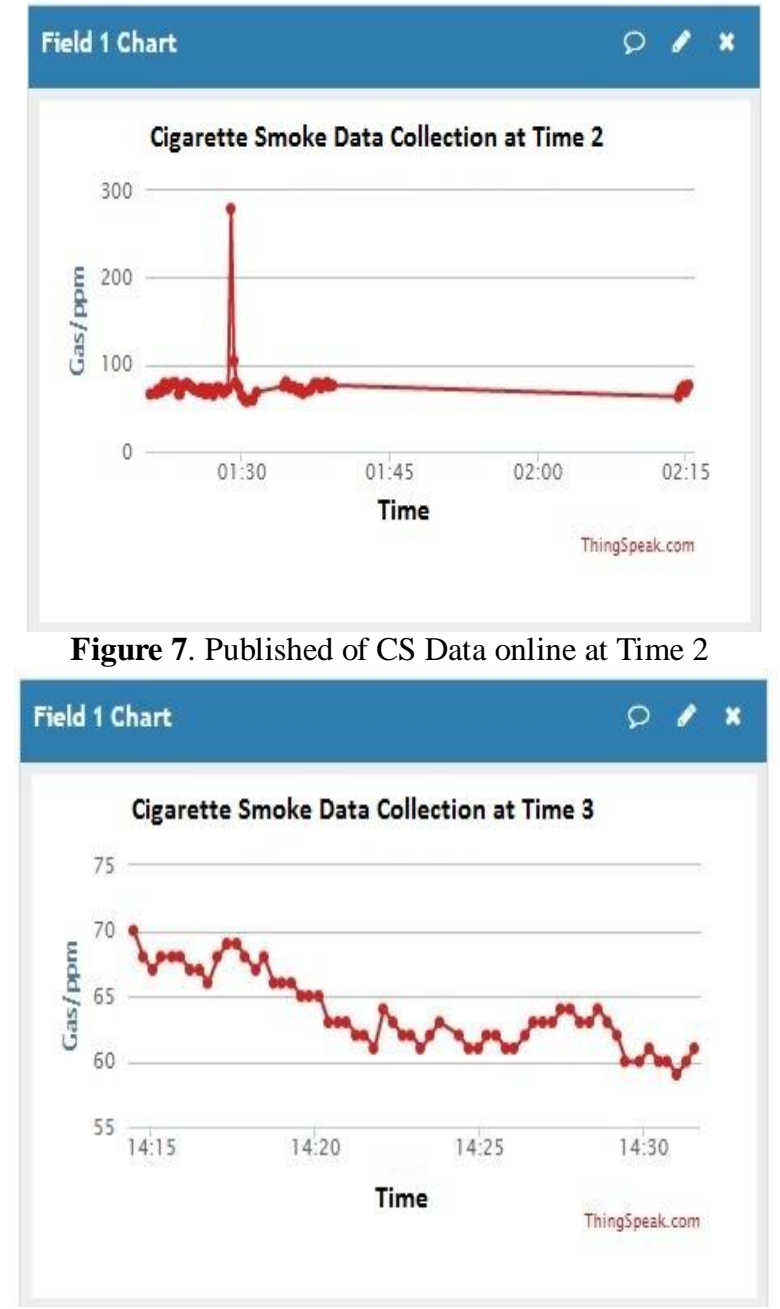

Figure 8. Published of CS Data online at Time 3

\section{CONCLUSION}

As a conclusion, this paper presents an adaptive CS detector system that manages to detect CS in an area. Three schedule times have been tested that collected three differences CS data collected which presents the difference of time compared to distance and type of condition that are open and air condition areas. The system also benefits where collected data can be published online on webpages and kept as a monitoring system in certain identified area purposely to monitor CS gas for safety environment. This system using Arduino assembly language programs on a windows PC since it is using Arduino as a microcontroller. The program is created into the hardware system called Arduino UNO, and the hardware is functioning according to the instruction program. The prototype system used ESP8266 Wi-Fi module as a device that transfer data from Arduino to webpages. Results present adaptive data collected in sample time. This research is significant for safety environment that able to maintain the clean air environment through online monitoring system and alert society on possible smoking places that they wish to avoid is possible.

\section{ACKNOWLEDGMENT}

Authors would like to thank Research Management Institute (RMC), Universiti Teknologi MARA Shah Alam for the support grant in publishing this research paper.

\section{REFERENCES}

[1] A. R. Iskandar et al., "A systems toxicology approach for comparative assessment: Biological impact of an aerosol from a candidate modified-risk tobacco product and cigarette smoke on human organotypic bronchial epithelial cultures," Toxicology in Vitro, vol. 39, pp. 29-51, 2017, doi: https://doi.org/10.1016/j.tiv.2016.11.009.

[2] S. Papoutsopoulou, J. Satsangi, B. J. Campbell, and C. S. Probert, "impact of cigarette smoking on intestinal inflammation-direct and indirect mechanisms," Alimentary Pharmacology \& Therapeutics, 2020.

[3] K. Bérubé et al., "In Vitro models of inhalation toxicity and disease: The report of a FRAME workshop," ATLA Alternatives to Laboratory Animals, Conference Paper vol. 37, no. 1, pp. 89-141, 2009.

[4] T. Nasution and M. Zarlis, "Embedded System for Detecting Cigarette Smoke Indoors using STM32 Microcontroller," in Journal of Physics: Conference Series, 2020, vol. 1566, no. 1: IOP Publishing, p. 012105.

[5] A. Jaafar, M. Kassim, C. K. Haroswati, and C. K. Yahya, "Dynamic home automation security (DyHAS) alert system with laser interfaces on webpages and windows mobile using rasberry PI," in 2016 7th IEEE Control and System Graduate Research Colloquium, ICSGRC 2016 - Proceeding, 2017, pp. 153-158, doi: 10.1109/ICSGRC.2016.7813319.

[6] M. Kassim, N. A. Sulaiman, and M. S. Y. Razali. Fan speed control on heat detector technique using zigbex wireless sensor network, Advanced Materials Research, vol. 622, pp. 1484-1491, 2013.

[7] A. Skinner, C. J. Stone, H. Doughty, and M. Munafo, "StopWatch: A smartwatch based system for passive detection of cigarette smoking," PsyArXiv Preprints.

[8] M. Kassim, C. K. Haroswati, C. K. Yahaya, and M. $\mathrm{N}$. Ismail, "A prototype of Web Based Temperature Monitoring system," in ICETC 2010 - 2010 2nd International Conference on Education Technology and Computer, 2010, vol. 5, pp. V5266-V5270, doi: 10.1109/ICETC.2010.5530066.

[9] E. Hickman and I. Jaspers, "Current E-Cigarette Research in the Context of Asthma," Current Allergy and Asthma Reports, vol. 20, no. 10, pp. 1-10, 2020. 
[10] M. Iasechko et al., "Determining the function of splitting the charged particles of the strongly ionized air environment in the openings of the case-screens of radio electronic means," International Journal of Advanced Trends in Computer Science and Engineering, Article vol. 8, no. 1.3 S1, pp. 19-23, 2019, Art no. 4, doi: 10.30534/ijatcse/2019/0481.32019.

[11] R. A. Rahman, N. S. A. Aziz, M. Kassim, and M. I. Yusof, "IoT-based personal health care monitoring device for diabetic patients," in ISCAIE 2017 - 2017 IEEE Symposium on Computer Applications and Industrial Electronics, 2017, pp. 168-173, doi: 10.1109/ISCAIE.2017.8074971.

[12] R. Hamzah, A. Supian, N. Jamil, and R. Roslan, "Automated smoking cessation pattern development through information retrieval," International Journal of Advanced Trends in Computer Science and Engineering, Article vol. 9, no. 1.1 Special Issue, pp. 483-489, 2020, Art no. 73, doi: 10.30534/ijatcse/2020/7991.12020.

[13] E. E. Adiba, E. A. Aahmed, and B. Youssef, "The green capacitated vehicle routing problem: Optimizing of emissions of greenhouse gas," in Logistics and Operations Management (GOL), 2014 International Conference on, 2014: IEEE, pp. 161167.

[14] J. W. Chang, M. Davids, J. Grigg, and R. Van ZylSmit, "The Differential Toxicity Of Inhaled Household Air Pollutants: Wood Smoke, Tobacco And Electronic Cigarettes," in C60. Indoor Air Pollutants: Biomass and Wood Smoke: Am Thoracic Soc, 2017, pp. A5988-A5988.

[15] W. Tsujita, H. Ishida, and T. Moriizumi, "Dynamic gas sensor network for air pollution monitoring and its auto-calibration," in Sensors, 2004. Proceedings of IEEE, 2004: IEEE, pp. 56-59.

[16] F. Liu, "Application of environmental management on energy saving and green house gas reduction in Beijing," in Management and Service Science (MASS), 2010 International Conference on, 2010: IEEE, pp. 1-6.

[17] A. Andrizal, B. Bakhtiar, and R. Chadry, "Detection Combustion Data Pattern on Gasoline Fuel Motorcycle with Carburetor System," International Journal on Advanced Science, Engineering and Information Technology, vol. 6, no. 1, pp. 107-111, 2016.

[18] D. Mendez, A. J. Perez, M. A. Labrador, and J. J. Marron, "P-sense: A participatory sensing system for air pollution monitoring and control," in Pervasive Computing and Communications Workshops (PERCOM Workshops), 2011 IEEE International Conference on, 2011: IEEE, pp. 344-347.

[19] V. Ramya and B. Palaniappan, "Embedded system for Hazardous Gas detection and Alerting," International Journal of Distributed and Parallel Systems (IJDPS) Vol, vol. 3, pp. 287-300, 2012.

[20] A. Raj, A. Viswanathan, and T. Athul, "LPG Gas Monitoring System," International Journal of Innovative Technology and Research (IJITR), vol. 3, no. 2, pp. 1957-1960, 2015.

[21] A. Lambebo and S. Haghani, "A Wireless Sensor Network for Environmental Monitoring of
Greenhouse Gases," in Proceedings of the ASEE Zone I Conference, 2014, pp. 1-4.

[22] P. S. Chandana, K. Sreelekha, A. M. L. Reddy, M. A. K. Reddy, and R. Senthamilselvan, "Internet of Things (IoT) Air And Sound Pollution Monitoring System," International Journal on Applications in Engineering and Technology, vol. 3, no. 1, pp. 18-21, 2017.

[23] M. Loh et al., "How Sensors Might Help Define the External Exposome," International journal of environmental research and public health, vol. 14, no. 4, p. 434, 2017.

[24] R. Nayak, M. R. Panigrahy, V. K. Rai, and T. A. Rao, "IoT Based Air Pollution Monitoring System," Imperial Journal of Interdisciplinary Research, vol. 3, no. 4, 2017.

[25] M. R. Hera, A. Rahman, A. Afrin, M. Y. S. Uddin, and N. Venkatasubramanian, "AQBox: An air quality measuring box from COTS gas sensors," in Networking, Systems and Security (NSysS), 2017 International Conference on, 2017: IEEE, pp. 191194. 